\title{
LA REGLA DE LA PREVISIBILIDAD DE LOS DAÑOS \\ CONTRACTUALES: UN EJEMPLO DE LA INFLUENCIA DE LA \\ DOCTRINA DE POTHIER EN LAS TRADICIONES DE DERECHO \\ CIVIL CONTINENTAL Y DE COMMON LAW
}

\section{HERNÁN CORRAL TALCIANI*}

RESUMEN: El trabajo ilustra la influencia del jurista francés del siglo XVIII, padre de la codificación, Robert Joseph Pothier en el acogimiento de la regla que limita la indemnización de los perjuicios contractuales a aquellos que se han podido prever a la época del contrato, tanto por los ordenamientos jurídicos de la tradición latino-continental como por los de Common law, aunque por diversas vías: por normas codificadas en los primeros y por un famoso precedente judicial en el segundo. Expone sus semejanzas y diferencias y observa que este punto en común de ambos sistemas puede contribuir a los esfuerzos que se desarrollan actualmente para unificar o armonizar el Derecho de los contratos.

PALABRAS CLAVE: Contrato - incumplimiento - daños contractuales previsibilidad - Pothier.

\section{ForseEABILITy OF THE STIPUlated DAMAGES RULE: AN EXAMPLE OF THE INFLUENCE OF POTHIER'S DOCTRINE IN CIVIL LAW AND COMMON LAW}

ABSTRACT: This essay shows the influence of Robert Joseph Pothier, French jurist of the $18^{\text {th }}$ century, pioneer in encoding related to the acceptance of the rule that limits the compensation of stipulated damages to those that have been foreseen to the expiration date of the agreement, both for the legal systems of the Continental Law tradition as for those

Abogado. Doctor en Derecho por la Universidad de Navarra (España). Profesor de Derecho Civil y Decano de la Facultad de Derecho de la Universidad de los Andes (CHILE). Correo electrónico: hcorral@uandes.cl. El trabajo es elaboración de la ponencia presentada por el autor a las VI Jornadas de Derecho Civil, realizadas en la Facultad de Derecho de la Universidad Gabriela Mistral los días 7 y 8 de octubre de 2009.

Fecha de recepción: 1 de diciembre de 2009.

Fecha de aprobación: 30 de diciembre de 2009. 
of the Common Law, though through different ways: by encoded rules in the former and throughout famous legal precedents in the latter. The article exhibits differences and similarities and exposes that this common point can contribute to the effort currently being displayed to unify and agree on contract Law.

KEY WORDS: Contract - breach- stipulated damages - forseeability Pothier.

\section{1) LA Regla de LA PREVISIBILIDAd EN LA DOCTRINA DE POTHIER}

\section{(1.1) ENUNCIACIÓN}

Sin duda entre las obras de literatura jurídica más influyentes de todos los tiempos, un lugar privilegiado debe ocupar el Traité des obligations de Robert Joseph Pothier (1699-1772), publicado por primera vez en dos volúmenes en 1761 y 1764 . Se ha dicho con razón que se trata de su obra maestra, que sirvió de base metodológica para la elaboración de los numerosos tratados que lo siguieron ${ }^{1}$. La sistematización de la materia, los conceptos forjados y hasta los ejemplos y casos que ilustran su pensamiento, cristalizarían después en el Derecho de las obligaciones de la época de codificación hasta nuestros tiempos.

Nuestra ponencia quiere centrarse, sin embargo, en uno de los puntos de este famoso e influyente tratado, y que figura en el Artículo III del capítulo II de su primera parte, destinado a tratar "De los dańos y perjuicios que resultan ya sea del incumplimiento de las obligaciones ya del retardo puesto a su ejecución", y más precisamente en los $\mathrm{N}^{\mathrm{os}} 160$ a $168^{2}$. Nos referimos a la regla que dispone que, en caso de incumplimiento de

Martínez de Aguirre, Carlos (2004). "Robert Joseph Pothier". En Domingo, Rafael (editor), Juristas Universales. Madrid/Barcelona: Marcial Pons, t. II, p. 584; ZimmermanN, Reinhard (2000). Estudios de Derecho Privado Europeo. Traducción de Antoni Vaquer Alox. Madrid: Civitas, p. 222, señala que el Traité no era original, aunque sí muy claro. Sin duda, los principales méritos de Pothier son el orden, la sistematicidad, la claridad y la sencillez, por lo que se ha dicho que "no inventa nada, pero descubre todo" (Dubouchet); Jeztaz, Philippe Jamin, Christophe (2004). La doctrine. Paris: Dalloz, p. 66, dicen que "en realidad, aunque Pothier no tenga la originalidad que se admira en sus grandes predecesores, él ha realizado la síntesis casi perfecta de todos los esfuerzos desarrollados en vista de la unificación del derecho francés".

2 Utilizamos en este trabajo la versión del Traité des Obligationes incluido en la edición completa de las obras de Pothier: Pothier, Robert Joseph (1821). Oeuvres de Pothier (tomo I). Editadas por M. Siffrein. Paris: Videcoq. En las citas posteriores se indica el número del Tratado y la página de esta edición. Para la traducción al español, en general, hemos seguido la versión de Pothier, Robert Joseph (1961). Tratado de las obligaciones. Buenos Aires: Talleres Gráficos Marypoint. 
una obligación contractual, el deudor responde no de todos los perjuicios causados, sino solo de aquellos previstos o que pudieron preverse a la época de celebración del contrato.

Ya en el No 160, Pothier enuncia esta regla: "Cuando no se puede reprochar al deudor dolo alguno, y que no es más que por una simple culpa el que haya dejado de cumplir su obligación, ya sea porque temerariamente se comprometió a lo que no podía cumplir, ya sea porque él se ha puesto después, por su culpa, fuera del estado de cumplir su compromiso; en ese caso, el deudor no es obligado más que a los dańos y perjuicios que se han podido prever, al momento del contrato [lors du contrat], que el acreedor podía sufrir de la inejecución de la obligación; pues se reputa que el deudor no se ha sometido más que a ellos" ${ }^{\text {. }}$

\section{(1.2) LAS FUENTES}

La doctrina de Pothier tiene su fuente en una Constitución de Justiniano del año 531 recogida en el Codex que limitaba la indemnización de dańos y perjuicios y fijaba el importe máximo de estos cuando se trataba de cosa cierta, al doble del valor de la cosa (C. 7. 47, ley única), y también en el tratado de Charles Dumoulin sobre los dańos y perjuicios que había comentado dicha ley y construido numerosas distinciones y subdistinciones (De eo quod interest Tractatus, 1584).

$\mathrm{La}$ originalidad de Pothier es que, si bien recoge el fundamento de la ley romana, a saber, que el deudor se reputa como no habiéndose entendido ni querido obligar por dańos más que a la suma a la cual él ha podido racionalmente prever que podían ascender a lo más dichos perjuicios, y no más allá, desecha el límite fijo del duplo ${ }^{4}$, por dos razones: por tratarse de algo arbitrario y por no tener vigencia en el país: "Esta ley de Justiniano, en tanto limita la moderación de los dańos y perjuicios excesivos, precisamente al doble del valor de la cosa, es en esto una ley arbitraria que no tiene autoridad de ley en nuestras provincias" 5 . Pero agrega que, en cuanto al principio que inspira a la ley, esto es, que el deudor no respon-

Pothier (1821) 160, 181. El texto original señala: "Lorsqu'on ne peut reprocher au débiteur auncun dol, et que ce n'est que par une simple faute qu'il n'a pas execute son obligation, soit parcequ'il s'est engagé témérairement à ce qu'il ne pouvoit accomplir, soit parcequ'il s'est mis depuis, par sa faute, hors d'état d'accomplir son engagement: dans ces cas le débiteur n'est tenu que des domages et intérêts qu'on a pu prévoir, lors du contrat, que le créancier pourroit souffir de l'inexécution de l'obligation; car le débiteur est cénsé ne s'être soumis qu'à ceux-ci".

4 Aunque Pothier no lo cita, ya había afirmado algo similar para el caso de incumplimiento del vendedor de la obligación de entregar la cosa, el jurista francés Jean Domat, en su más famosa obra: Domat, Jean (1844). Las leyes civiles en su orden natural. Traducción de Felio Vilarruelas y José Sardá. Barcelona: Imprenta de José Taulo, t. I, p. 152: los perjuicios "nunca deben hacerse extensivos a las consecuencias más lejanas e imprevistas". 
da más allá de lo que ha podido pensar, "siendo un principio fundado en la razón y equidad natural, nosotros debemos seguirlo y moderar conforme a ese principio los daños y perjuicios, cuando se encuentren excesivos, dejando esta moderación al arbitrio del juez" 6 .

Pothier, además, amplía este criterio a los casos en los llamados daños extrínsecos, esto es, que se padecen no en la cosa objeto del contrato sino en otros bienes: "Empero, aun en relación a esos dańos extrínsecos, se debe usar de moderación cuando se encuentren excesivos, y no se debe condenar al deudor más allá de la suma en la cual ha podido pensar que podrían alcanzar en lo más alto"7.

El tratado de Dumoulin es constantemente citado en estos párrafos de la obra, por lo que resulta manifiesta su influencia. La originalidad de Pothier fue haber reducido las múltiples reglas del antiguo comentarista francés a una sola: solo se responde de los dańos que se han previsto o podido prever, y todos los casos son reconducidos a este principio fundamental. El material estaba preparado para que la regla fuera convertida en una norma del Código Civil.

\section{(1.3) LA FUNDAMENTACIÓN}

El fundamento que ofrece Pothier para esta delimitación de los dańos contractuales parece residir en la voluntad de las partes. Al explicar la ley del Código de Justiniano nos dice que "El principio sobre que se funda esta decisión, es el de que las obligaciones que nacen de los contratos no pueden formarse más que por el consentimiento y la voluntad de las partes. Ahora bien, el deudor, al obligarse al pago de dańos y perjuicios que resultarían de la inejecución de su obligación, se reputa como no habiéndose entendido ni querido obligar más que hasta la suma a la cual él ha podido racionalmente prever que podían montar a lo más los dichos daños y perjuicios, y no más allá" ${ }^{8}$; a lo que agrega: "dicho se está, pues, que cuando esos daños y perjuicios suben a una suma excesiva, a la cual el deudor jamás ha podido pensar que pudieran subir, deben reducirse y moderarse a la suma a la que se puede racionalmente pensar que podrían subir como máximo; pues ha de reputarse el deudor como no habiéndose obligado a más"?. 
Vuelve a insistir en este fundamento un poco más adelante: "Esta moderación que se practica en relación a los daños y perjuicios ordinarios, está fundada sobre ese principio que nosotros hemos expuesto más arriba, esto es, que un deudor no puede reputársele como habiéndose querido obligar por dańos y perjuicios a una más grande suma que aquella a la cual él ha podido pensar que podrían subir al más alto grado los daños y perjuicios a los cuales se sometiera, en caso de inejecución de su obligación" 10 .

De allí que, si bien respecto de la cosa objeto del contrato los dańos sufridos son considerados previsibles ${ }^{11}$, los daños extrínsecos, es decir, aquellos que conciernen a intereses diversos de la cosa, no se entienden previstos, salvo que el deudor haya asumido el riesgo "de una manera tácita o expresa en caso de incumplimiento de su obligación"12.

Si bien la voluntad presunta del deudor justifica que se le haga responsable solo hasta los perjuicios previsibles, Pothier añade que esta moderación constituye también "un principio fundado en la razón y equidad natural"13.

\section{(1.4) LOS EJEMPLOS}

Pothier, como de costumbre, es pródigo en ejemplos prácticos. Habiendo sido juez de Orleans tantos años no es raro que dedique tanta importancia a los casos para ilustrar las normas.

Respecto de los daños en la cosa, pone dos ejemplos para entender la regla de la previsibilidad: la obligación de entregar un caballo y la obligación del arrendador de proporcionar el uso de la cosa arrendada al arrendatario.

En el primero, señala que si alguien se obliga a entregar un caballo y no cumple su obligación, y entre tanto el comprador hubiera tenido que comprar otro caballo a un precio mayor, este mayor precio debe ser indemnizado por el deudor incumplidor. Pero si el comprador era un canónigo que, por falta de la entrega oportuna del caballo, no pudo llegar a tiempo al lugar de su beneficio a recoger sus frutos, el deudor no sería responsable de esta pérdida, pues se trataría de un perjuicio que no se ha previsto ni puede decirse que el deudor se hubiere sometido al contra$\operatorname{tar}^{14}$. Solo si en una cláusula del contrato se hubiera contemplado que debía entregarse el caballo para que el canónigo pudiera llegar oportunamente a su beneficio, el deudor debería responder ya que el riesgo del perjuicio se había previsto y expresado ${ }^{15}$.

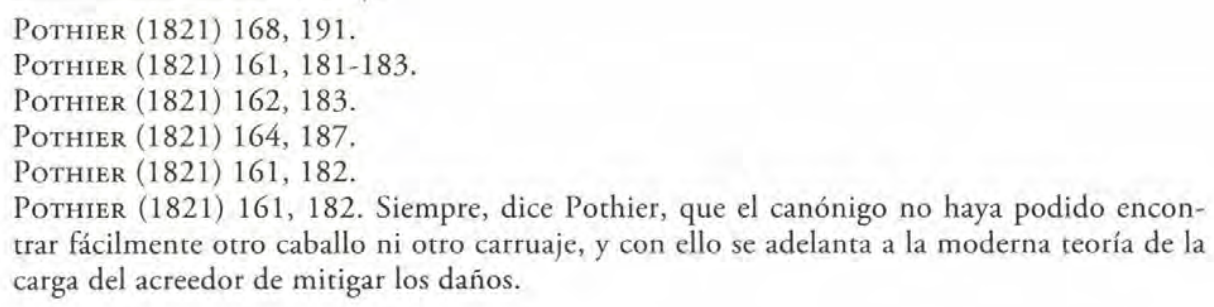
trar fácilmente otro caballo ni otro carruaje, y con ello se adelanta a la moderna teoría de la carga del acreedor de mitigar los daños. 
En el segundo ejemplo, si el arrendatario es expulsado por el verdadero propietario, el arrendador deberá indemnizar los perjuicios resultantes del cambio de local, como los del aumento del precio del arrendamiento ocurrido mientras duró el contrato. Pero si el arrendatario ha establecido un comercio en la casa arrendada y alega que por su desplazamiento sufre perjuicios, el arrendador no será obligado ya que ellos siendo extrańos a la convención no fueron previstos en el contrato ${ }^{16}$. Nuevamente, si se arrendó la casa para convertirla en posada, el daño de la pérdida comercial siendo un riesgo previsto debe ser incluido en la indemnización ${ }^{17}$.

Otros ejemplos coloca Pothier pero que parecen desmarcarse de la regla de la previsibilidad para situarse en el deber del vendedor de informar la calidad defectuosa de la cosa vendida. Así, si alguien compra unos maderos para apuntalar una casa, la que se viene abajo por la mala calidad de la madera vendida, distingue entre si el vendedor no era hombre entendido en el asunto, por no ser de su oficio el conocer la calidad de los maderos y que ignoraba sus defectos, caso en el cual no responde por el dańo causado; y si el vendedor era un carpintero u hombre del oficio, en el que será responsable, incluso si fuera verdad que él los creía buenos y suficientes, pues se trataría de una ignorancia inexcusable en razón de ofi$\mathrm{cio}^{18}$.

Pero de aquí, retorna el maestro de Orleans al problema de la previsibilidad: si el carpintero ha vendido los maderos para sostener cierta casa y el comprador luego hace uso de ellos para sostener otra de mayor envergadura que se viene abajo, el vendedor no responderá por el valor de esta, sino solo por la de la casa pequeńa para la que fueron vendidos ${ }^{19}$.

Siguiendo a Dumoulin, prosigue con el ejemplo y seńala que en caso de responder el carpintero por la ruina de la casa que se apuntala con los maderos defectuosos, no se entienden incluidos los dańos que hubieren experimentado los muebles en caso de haberlos, ya que como normalmente se desamuebla una casa que se apuntala, el vendedor no ha podido prever este riesgo, salvo estipulación expresa ${ }^{20}$. Por el contrario, si se trata del albañil que construye una casa que luego se viene abajo, deberá indemnizar los muebles que se destruyan por la ruina, ya que el constructor no podía ignorar que se incluirían muebles dentro de la casa, dado que no puede habitarse sin muebles ${ }^{21}$.

\footnotetext{
Pothier (1821) 161, 182-183.

POTHIER (1821) 162, 183.

Pothier (1821) 163, 184.

POTHIER (1821) 163, 184-185.

Pothier (1821) 163, 185.

Pothier (1821) 163, 185-186.
} 
Un nuevo caso coloca Pothier para ilustrar la aplicación de la limitación de la Ley de Justiniano. Se trata de alguien que compra unas vińas en una provincia lejana a su domicilio por el precio de 4.000 libras ( $i$ vres). Al momento de la compra, el vino que producía la heredad, la única fuente de producción, se cotizaba en un bajo precio porque no tenía mercado para exportarlo. Posteriormente el rey manda a hacer un canal que facilita la exportación, aumentando el precio del vino en un cuádruplo o más de su valor. Con ello, la finca sube de precio de 4.000 a 16.000 libras. Si se lanza de esta propiedad al comprador, el vendedor en principio debería indemnizarle el valor de lo perdido, esto es, más de 16.000 libras. Por la ley, sin embargo, se limitarán esos daños a lo más al duplo, esto es, a 8.000 libras, comprendiendo la restitución del precio de 4.000 libras $^{22}$.

Dos nuevos ejemplos da Pothier para ilustrar la aplicación de la regla respecto de los dańos extrínsecos. Si alguien vende unos toneles de mala calidad y el comprador sufre la pérdida del vino que introdujo en ellos, ya no puede aplicarse la regla del duplo del valor de los toneles, y deberá indemnizarse todo el costo del vino perdido, pero siempre que dicha pérdida haya sido previsible. Así, si en vez de vino el comprador introduce un vino extranjero u otro licor de un precio inmenso el vendedor solo responderá hasta el monto del valor del mejor vino del país y no más ${ }^{23}$. De igual modo, el constructor de la casa que se arruina responde de la destrucción de los muebles, pero no de la pérdida de un manuscrito o de piedras preciosas ("pierreries") de un inmenso precio ${ }^{24}$.

\section{(1.5) LA EXCEPCIÓN DEL DEUdOR DOLOSO}

La regla de la previsibilidad, según Pothier, no se aplica cuando el deudor ha actuado con dolo: "en ese caso el deudor es responsable indistintamente de todos los daños e intereses que yo he sufrido, a los cuales su dolo ha dado lugar..." 25 .

La razón de la diferencia la explica Pothier con referencia a la fundamentación de la regla que es que no puede reputarse que el deudor haya querido obligarse a más de lo previsible, principio que "no puede tener aplicación a los dańos y perjuicios que resulten del dolo, por cuanto quien comete dolo, se obliga indistintamente velit, nolit, a la reparación del dańo [tort $]$ que el dolo causara" 26 . Sigue nuevamente a Dumoulin.

Con ello, el deudor doloso responde por los daños imprevisibles. Así, en el famoso ejemplo de Pothier, el vendedor que vende a sabiendas y con

Pothier (1821) 164, 186-187.

Pothier (1821) 165, 188-189.

Pothier (1821) 165, 189.

Pothier (1821) 166, 189.

Pothier (1821) 168, 191. 
disimulo una vaca enferma, responde no solo por la pérdida de esa vaca sino por el resto del ganado al que se ha comunicado el contagio ${ }^{27}$. Pero, según Pothier, este deudor no debe responder de consecuencias que no son necesarias ni próximas y que pueden tener otras causas: por ejemplo, si por la pérdida del ganado contagiado no se pudo cultivar la tierra, no se pagaron las deudas y el predio fue subastado ${ }^{28}$.

Con todo, advierte, el jurista francés "Sin embargo, debe dejarse a la prudencia del juez, aun en caso de dolo, usar de alguna indulgencia en la tasación de daños y perjuicios" 29 .

\section{2) la recepción de la doctrina de Pothier en el Derecho LATINO CONTINENTAL}

La doctrina de Pothier se plasmará en el Código Civil francés de 1804, en dos artículos. El art. 1150 dispondrá que "El deudor no está obligado a más que a los daños y perjuicios que han sido previstos o han podido preverse al tiempo del contrato, cuando no ha sido por dolo que su obligación no se ha ejecutado". El siguiente precepto, el art. 1151, señalará que "En el caso que la inejecución de la convención resulte de dolo del deudor, los dańos y perjuicios no deben comprender, respecto de la pérdida sufrida por el acreedor o de la ganancia de la que ha sido privado, sino aquellos que sean una consecuencia inmediata y directa de la inejecución de la convención". El Código no recogió la facultad del juez para moderar los perjuicios incluso del deudor doloso que propiciaba Pothier $^{30}$.

Del Código francés la regla de la previsibilidad del daño contractual se expandió a todos los ámbitos en los que dicho Código ejerció influencia. Aparece así en el Código Civil belga (art. 1150), en el Código Civil argentino (arts. 520 y 521, reformado posteriormente por la Ley No 17.711, de 1968), en el Código Civil español (arts. 1107 y 1108) y en el Código Civil italiano de 1865 (arts. 1128 y 1229) y en el vigente de 1942 (arts. 1223 y 1225).

La regla, en cambio, no fue recibida por el Código Civil alemán de 1900 , el B.G.B. ( $\$ \$ 249$ y 252), ni por aquellos que han sufrido la influencia germánica: Código civil suizo (art. 97), Código Civil holandés (art. 98 del libro VI).

Pothier (1821) 166, 189.

Pothier (1821) 167, 189-191.

POTHIER (1821) 168, 191.

Domínguez Hidalgo, Carmen (2000). El daño moral. Santiago: Editorial Jurídica de Chile, t. II, p. 499, nota 16, seńala que, si bien los redactores invocaron que el acreedor tenía derecho a la indemnización completa, se observa en el fondo de la decisión la idea de reducir al máximo las intervenciones del arbitrio judicial. 
El Código Civil chileno recepcionó la doctrina de Pothier fusionando en una sola norma los dos artículos del Código francés. El art. 1558, inciso $1^{\circ}$, dispone que "Si no se puede imputar dolo al deudor, solo es responsable de los perjuicios que se previeron o pudieron preverse al tiempo del contrato; pero si hay dolo, es responsable de todos los perjuicios que fueron una consecuencia inmediata o directa de no haberse cumplido la obligación o de haberse demorado su cumplimiento" ${ }^{31}$.

\section{3) LA RECEPCiÓN DE LA REgLA EN EL COMMON LAW}

\section{(3.1) La influencia de Pothier en el Derecho de contratos ANGLOAMERICANO DEL SIGLO XIX}

Insospechadamente la doctrina de Pothier emigró hacia Inglaterra y Estados Unidos de América, siendo uno de los pocos casos en los que el Derecho continental ha determinado el forjamiento de un precedente que ha devenido en medular del sistema contractual de los países de sistema de Common law.

En el Derecho de los contratos del Common law se sostiene que los daños indemnizables están limitados por la regla de lo que se denomina la regla de "unforeseeability" o "contemplation rule". Así la expresa uno de los principales tratadistas contemporáneos, E. Allan Farnsworth: "Bajo esta limitación, la parte que incumple no es responsable por dańos, sea ante un incumplimiento parcial o total, si esa parte, al tiempo de contratar, no tenía razón para preverlo como probable resultado del incumplimiento" 32 .

El surgimiento de esta regla en el Common law debe su origen a una recepción de la doctrina de Robert Joseph Pothier y su Tratado de las Obligaciones.

Por de pronto, se sabe que Pothier gozó una gran autoridad entre los escritores del Common law, sobre todo en los comienzos del siglo XIX. El primero que se fijó en la maestría de las obras de Pothier y de su

31 Sobre la interpretación de este artículo puede verse a Corral Talciani, Hernán (2008). "Causalidad y previsibilidad en la responsabilidad contractual". En Tatiana Vargas (editora): La relación de causalidad. Análisis de su relevancia en la responsabilidad civil y penal, Cuadernos de Extensión Jurídica 15. Santiago: Universidad de los Andes, pp. 115-179. En relación con la aplicación del criterio de la previsibilidad al daño moral contractual y con amplia revisión de la regla y un análisis crítico sobre la base de la tendencia a la unificación de los regímenes de responsabilidad: cfr. Domínguez (2000) II, 493-592. También sobre el dańo moral contractual, Barrientos Zamorano, Marcelo (2007). "Los dańos extrapatrimoniales que se previeron o pudieron prever al tiempo del contrato". Revista Chilena de Derecho, vol. 34, No 1, pp. 7-22.

32 Farnsworth, E. Allan (2004). Farnsworth on Contracts, $3^{\text {a }}$ edic. New York: Aspen, t. III, p. 255. 
tratado de las obligaciones fue Sir Williams Jones ${ }^{33}$. Jones en su célebre y difundido An Essay on the Law of Bailments, cuya primera edición data de 1781, elogia ampliamente al jurista francés: exhorta a leerlo "again and again" y se atreve a decir que su doctrina debe ser considerado "law at Westminster as well as at Orleáns". Finaliza su elogio diciendo que si él lograra dar a conocer las obras de Pothier a sus compatriotas, sentiría que con ese solo hecho habría cumplido con el deber de la profesión ${ }^{34}$.

El influjo de Pothier fue potenciado cuando su Tratado de las obligaciones fue objeto de traducciones al inglés en Estados Unidos en 1802 y en Inglaterra en 1806, como "A treatise on Obligations" y como " $A$ Treatise on the Law of Obligations or Contracts", respectivamente ${ }^{35}$. Estas traducciones fueron muy cotizadas, al parecer porque coincidió con una época en que los jueces y abogados del Common law estaban aspirando a una mayor racionalización de su sistema a través de grandes principios generales ${ }^{36}$. Señala Zimmermann que esta obra de Pothier "alcanzó en Inglaterra a lo largo del siglo XIX un prestigio sin parangón con ninguna obra académica"37.

Así lo afirma Аттун, P. S. (1979). The rise and fall of freedom of contract. Oxford: Clarendon Press. p. 399.

Jones, Williams (1828). An Essay on the Law of Bailments. 3a edic. Philadelphia: O. Halsted y John Grigg, p. 29. El párrafo completo es el siguiente: "At the time when this author wrote, the learned $M$. Pothier was composing some of his admirable Treatises on all the different species of express or implied contracts; and here I seize, with pleasure, an opportunity of recommending those treatises to the English lawyer, exhorting him to read them again and again; for, if his great master Littleton has given him, as it must be presumed, a taste for luminous method, apposite examples, and a clear manly style, in which nothing is redundant, nothing deficient, he will surely be delighted with works, in which all those advantages are combined, and the greatest portion of which is law at Westminster as well as at Orleans: for my own part, I am so charmed with them, that, if my undissembled fondness for the study of jurisprudence were never to produce any greater benefit to the public, than barely the introduction of Pothier to the acquaintance of my countrymen, I should think that I had in some measure discharged the debt which every man, according to Lord Coke, owes to his profession". El mismo Jones en nota informa que el "el ilustre autor murió en 1772".

Puede verse: Pothier, Robert Joseph (1802). A Treatise on Obligations, Considered in a Moral and Legal View. Newbern, N. C., Martin \& Orden; Pothier, Robert Joseph (1826). A Treatise on the Law of Obligations or Contracts. Traducción de Williams David Evans. London: Strahan. A. En la edición norteamericana, se inserta como suficiente justificación de la traducción los elogios de Sir Willams Jones en su Law of Bailments (p. iii). En la edición inglesa, posteriormente reimpresa en 1826 (Philadelphia: Robert H. Small), el traductor Williams David escribe una amplia introducción donde también seńala que la recomendación de Jones hace superfluo cualquier añadido sobre la importancia del tratado, lo que es confirmado por el hecho de que la doctrina de Pothier ha sido citada con aprobación en "nuestros propios procedimientos judiciales" (t. I, p. 86).

Dice Aтryah (1979) 399, que "Cuando apareció la traducción inglesa del Derecho de las obligaciones de Pothier en 1806, fue ávidamente aprovechada por los abogados y jueces ingleses porque proveía los principios generales del Derecho de Contratos que los abogados modernos ingleses estaban buscando especialmente".

Zimmermann (2000) 222. Cita la sentencia del juez Best de 1822 que seńala que "la autoridad de Pothier es tan alta como podría ser, similar a la decisión de una Corte de Justicia de este país" (Cox $v$. Troy, 1822, Barnewall and Alderson's Reports 474, p. 480). 
Se prepara así la acogida de la regla de la previsibilidad contenida en el Traité de Pothier. Una primera recepción, de carácter legislativo, la tuvo a través del Código Civil de La Louisiana que siguió literalmente en este punto al Código francés ${ }^{38}$.

Pero se trataba de un sistema codificado, y no aún del Common law. En este ámbito la recepción fue primeramente doctrinal. Ya los Commentaries de Kent citaban a este respecto a Pothier ${ }^{39}$. Fue la clásica obra de Daniel Chipman, titulada An essay on the Law of Contracts, publicada en 1822, la que tomó como modelo a Pothier por medio de remisiones a los números de su Traité. Al tratar de los daños, Chipman distingue entre los casos de variación de valor de la cosa entre el momento en que se debía entregar y la entrega efectiva, en los cuales esa es la medida de los daños "porque las partes no tenían en contemplación ningún tipo de daños extrínsecos”, y aquellos en los que el acreedor pretende cobrar más perjuicios que el valor de la propiedad al tiempo y lugar de la entrega, los que solo se deberán si la propiedad fue comprada con un propósito específico y este fue expresado en el contrato. Aun cuando no se haya declarado es posible presumir la "contemplation" de las partes como si una parte se obliga a entregar a la otra una cantidad de ladrillos suficientes para construir una casa y por su incumplimiento la otra parte no puede construir la casa hasta el año siguiente y debe dejar las fundaciones expuestas a los fríos del invierno, entonces se deberán estos dańos, ya que "en tales casos se presume que las partes del contrato, en el tiempo en que se celebró, tuvieron en consideración [contemplation] tales dańos extrínsecos, y el riesgo de ser producidos, en caso de un incumplimiento del contrato, era previsto [foreseen]". En cambio, si la parte solo entrega una nota a mano por 10.000 ladrillos para ser entregados el 1 de julio próximo, no se podrían cobrar los daños del caso anterior, ya que "no aparece que el riegos de tales dańos extrínsecos fuera previsto por las partes al tiempo del contrato". Cita en apoyo el No 162 del Traitét 4 .

El segundo hito de la recepción doctrinal de la regla la constituye la aparición del tratado, dedicado monográficamente al tema de la avaluación de los perjuicios, del ilustre jurista inglés, Theodore Sedgwick, publicado por primera vez en 1847, con el título $A$ treatise on the measure of damages. Sedgwick apunta que la regla del Common law que limita la indemnización de los llamados "remote damages", es demasiado vaga e intenta preci-

38 El art. 1298 en sus $N^{\text {os }} 1$ y 2 repetía las normas de los arts. 1150 y 1151 del Code. Puede verse SaInt-Joseph, Anthoine (1856). Concordance entre les Codes Civils étrangers et le Code Napoleón. $2^{\text {a }}$ edic. Paris: Cotillon, Libraire du Conseil d’État, t. II, p. 530. es citado profusamente, por ejemplo, al tratar del contrato de venta en las pp. 363, 367, $368,373,385,386,387,390,392$ y 397

40 Chipman, Daniel (1822). An essay on the Law of Contracts, for the payment of specific articles. Middlebury: J. W. Copelan, pp. 121-122. 
sarla. Para ello da información del Derecho comparado, apuntando a los criterios de la jurisprudencia escocesa, pero principalmente de la doctrina francesa, cuyos autores califica como "the writers of the modern civil law" 41 . El primero que cita es Pothier en su tratado de las obligaciones, reproduciendo no solo la regla de la previsibilidad sino prácticamente todos los ejemplos del Traité: el de la compra del caballo, el del arrendamiento que se termina anticipadamente, el del carpintero y hasta el de la vaca enferma ${ }^{42}$. Pero también traduce los arts. 1149, 1150 y 1151 del Código Civil francés, los que ofrece en su texto original francés en nota, así como comentaristas de este como Duranton y Toullier ${ }^{43}$. No parece satisfecho del panorama francés, ya que sostiene que la discusión curiosamente ilustra que aparentemente no existe una regla fija que mida los daños ${ }^{44}$. Con todo, finalmente, cita un caso fallado en Louisiana en 1839, donde se reconoce la autoridad de Pothier y Toullier, y se sostiene que "los dańos que una parte puede reclamar del incumplimiento de un contrato, son aquellos que son producidos y causados por el incumplimiento, y pueden razonablemente ser supuestos como habiendo sido comprendidos en la contemplación de las partes al tiempo del contrato" 45 , y señala "esta es quizás la más clara y definitiva línea que puede ser extraída en la materia": "this is perhaps the clearnest and most definite line can be drawn in the matter" 46 .

La recepción doctrinal es seguida por algunos fallos, y no ya de Louisiana donde impera un sistema codificado, sino en el propio ámbito del Common law. Así, en 1839, la Corte de Nueva York invocó a Pothier en el caso Blanchard vs. Ely ${ }^{47}$. En 1853, la Court of Exchequer falló el caso Water vs. Towers ${ }^{48}$ en el que rechazó el lucro cesante demandado por estimarlo contingente ("mere contingent damage"), apoyándose en el criterio de la "contemplation". Si bien la Corte no citó a Pothier, invocó la autoridad de Kent, que como hemos dicho lo considera en sus notas.

\section{(3.2) LA CONSAGRACIÓN DE LA REGLA DE LA PREVISIBILIDAD EN EL CASO HADLEY VS. BAXENDALE}

En este panorama, se dicta el fallo que terminará por consagrar y acuñar la formulación de la regla en el Common law y se transformará en

Sedgwick, Theodore (1852). A treatise on the measure of damages or, an inquiry into the principes wich govern amount of compensation recovered in suits at law. $2^{\text {a }}$ edic. New York: John S. Voorhies, Law bookseller and Publisher, p. 58.

SEDGWICK (1852) 60-63.

SEDGWICK (1852) 64.

Williams v. Barton, 18 Louisiana R., 404; 13 La. 404, 410 (1839)

SEDGWICK (1852) 67.

Blanchard vs. Ely, 21 Wendell *348-350 (N.Y. 1839).

Water vs. Towers 8 Ex. 401; 155 Eng. Rep. 1404 (1853). 
el leading case de toda esta materia. Se trata de Hadley vs. Baxendale fallado por la Court of Exchequer en $1854^{49}$, uno de los casos más influyentes y conocidos del sistema jurídico angloamericano.

Los hechos que suscitaron la sentencia fueron, en síntesis, los siguientes ${ }^{50}$ : Joseph y Jonah Hadley eran propietarios de un molino situado en Gloucesster cuando el 11 de mayo de 1853 se rompió un cigüeñal (crankshaft). Para conseguir que se fabricara uno nuevo, debían enviar el roto como modelo a Greenwich donde estaba la empresa que podía fabricarlo. El 14 de mayo de 1853 la pieza fue encargada a la empresa de transportes (carrier), Pickford \& Co., para que la trasladara desde Gloucesster a Greenwich. El empleado del transportista informó que el traslado duraría un día, por lo que la piedra arribaría a Greenwich el día siguiente: 15 de mayo. No obstante, la entrega se retrasó hasta cinco días, con lo cual los propietarios del molino recibieron la pieza nueva varios días más tarde de lo previsto. Durante este tiempo, el molino estuvo paralizado y sin poder producir. Los propietarios demandaron a Pickford \& Co. y a la persona de su "managing director", Joseph Baxendale, solicitando que se les indemnizara con 300 libras por lo que nosotros llamaríamos lucro cesante derivado de la falta de producción del molino: en el sistema inglés este tipo de años es denominado "lost profits". La demanda se basó en dos cargos ("counts"): el primero es basado en el incumplimiento del contrato ("assumpsit for breach of contract"), mientras el segundo se fundaba en la infracción de los derechos del "carrier" fijados por el Common law. Los demandados rechazaron el primero, mientras que por el segundo pagaron en el tribunal 25 libras. Los demandantes introdujeron un "nolle prosequi" respecto del primero, pero en cuanto al segundo alegaron que el monto pagado no era suficiente para compensar las pérdidas. El juez de primera instancia, Crompton, instruyó al jurado para dictaminar si la entrega fue hecha en un tiempo razonable y cuáles eran los dańos causados a los demandantes por la demora en la entrega. El jurado entregó un veredicto por el cual obligaba a los demandados a pagar otras 25 libras además de las ya abonadas. Los demandados alegaron que el jurado había sido mal instruido: "misdirection" y obtuvieron una "rule nisi" para pedir un nuevo juicio. El 1 de febrero de 1854 los demandantes expusieron su posición ante la Court of Exchequer, ante los jueces (barons) Parke, Anderson, Platt y Martin. La sentencia de la Corte fue expuesta por Anderson. En ella, se afirmó que el jurado no había sido correctamente instruido en el primer juicio, ya que era necesario darle una regla definida que pudiera guiar su pronunciamiento. Pero yendo más allá, la sentencia Journal of Legal History, 15, 1, pp. 44-49. 
explicitó cuál era la regla que debía ser aplicada por los jurados en estos casos. Y esta es la parte más relevante del fallo, donde aparece explicitada la doctrina de la previsibilidad contractual:

"... we think the proper rule in such a case as the present is this:--Where two parties have made a contract which one of them has broken, the damages which the other party ought to receive in respect of such breach of contract should be such as may fairly and reasonably be considered either arising naturally, i.e., according to the usual course of things, from such breach of contract itself, or such as may reasonably be supposed to have been in the contemplation of both parties, at the time they made the contract, as the probable result of the breach of it" (Nosotros pensamos que la regla apropiada en un caso como el presente es esta: Cuando dos partes han celebrado un contrato que una de ellas ha incumplido, [la indemnización de] los daños que la otra parte debe recibir por dicho incumplimiento deben ser aquellos que justa y razonablemente puedan ser considerados como naturalmente causados, esto es, conforme al curso usual de las cosas, por el incumplimiento mismo del contrato, o aquellos que, razonablemente, pueda suponerse que fueron contemplados por ambas partes como el probable resultado del incumplimiento, en el momento en que ellas celebraron el contrato") $)^{51}$.

El principio de la Corte puede descomponerse en dos reglas: la primera, que no ha sido objeto de mayor discusión, es que el contratante perjudicado debe ser indemnizado de los dańos que puedan considerase como razonablemente surgidos del incumplimiento por el curso usual de las cosas. La segunda es la más significativa, y la que regirá en todo el Derecho de los contratos de ahora en adelante: si se trata de dańos que no se pueden entender como surgidos naturalmente del incumplimiento (los llamados "consequential damages"), ellos solo se pueden otorgar al deman-

En realidad, la Corte no se limitó a establecer la regla sino que la aplicó al caso diciendo que la pérdida de ganancias por el retraso de la pieza quebrada no era previsible. Anderson expuso que la Corte entendió que cuando se envió la pieza no se informó a los empleados del transportista que sin ella el molino no podía funcionar, con lo cual el nuevo tribunal necesariamente fue, en palabras de Faust (1994) 51, una "simple farsa". Más aún, este autor informa que no es para nada claro que los demandados no hubieran sabido las circunstancias del molino y a que en el caso existía evidencia de que la paralización del molino fue informada, si bien no al momento de la entrega de la pieza, pero sí el día anterior ( 13 de mayo) cuando se consultó al carrier cuánto demoraría el traslado. Otra crítica al fallo, también planteada por Faust (1994) 48 y 51, es que en realidad el caso debió haberse tratado con los criterios del Derecho de Torts y no de Contracts, ya que el primer cargo, que se basaba en el incumplimiento contractual, fue desistido, mientras se prosiguió con el segundo que invocaba ya no el contrato sino los deberes legales del transportista y cuya infracción constituía un tort y no un "breach of contract". 
dante cuando puede razonablemente suponerse que han sido contemplados por las partes al tiempo de celebración del contrato. Si se entiende que el primer caso no es más que un ejemplo de la segunda regla, la doctrina de Hadley consagra la previsibilidad al tiempo del contrato como límite a la extensión de la responsabilidad contractual ${ }^{52}$.

Aunque la sentencia de Hadley vs. Baxendale no citó expresamente a Pothier ${ }^{53}$, es algo indiscutido en el Common law que la regla asentada por el maestro francés en su Traité fue "su inmediato modelo" 54 . De hecho los abogados del demandante citaron expresamente el tratado de Sedgwick, en la parte donde seńala que Pothier y el Derecho francés hacen responsable al deudor que actúa con culpa solo de aquella parte de los dańos que puede razonablemente suponerse que las partes contemplaron como probable resultado de la naturaleza del acuerdo, mientras que el deudor que actúa con dolo o fraude es responsable de todas las consecuencias. El juez Parke interrumpió para hacer ver que "the sensible rule" aparece en los arts. 1149, 1150 y 1151 del Código Civil francés, traducidos por Sedgwick, y que son reproducidos en los antecedentes del caso. También los abogados del demandado adujeron a Sedgwick, aunque se asilaron más bien en que la pérdida de beneficios era una consecuencia remota o indirecta ${ }^{55}$.

La regla de Hadley vs. Baxendale no distingue entre el deudor que actúa con culpa y el que incurre en dolo, por lo que en esto la doctrina de Pothier no fue seguida. Es posible notar una resistencia a la distinción

Como señala Aтryah, P. S. (1995). An Introduction to the Law of Contract. Oxford: Clarendon Press, p. 465, en realidad, la regla del caso es una sola: la de la previsibilidad, ya que la primera no es más que una forma para decir que el deudor es responsable del daño razonablemente previsible, ya que "lo normal es siempre razonablemente previsible". En el mismo sentido, aunque en un planteamiento crítico al fallo y a la regla contemplada en él, EisenberG, Melvin Aron (1992). "The principle of Hadley v. Baxendale". California Law Review 80, p. 566: "la primera regla es simplemente un caso especial de la segunda: si un determinado tipo de daño surge 'naturalmente, esto es, de acuerdo al curso natural de las cosas' desde el incumplimiento de determinado contrato (la primera regla), entonces un vendedor siempre tendrá razón para prever que el determinado tipo de daños son el resultado probable del incumplimiento (la segunda regla)".

Debemos corregir nuestra afirmación en CorRal (2008) 127, en el sentido de que Pothier "fue expresamente invocado en el juicio Hadley vs. Baxendale". En realidad, Pothier mismo no fue mencionado aunque sí se consideró su enseńanza a través del tratado Sedgwick, como se precisa aquí.

54 Faust (1994) 42. En este sentido, Corbin, Arthur Linton (1964). Corbin on Contracts. St. Paul, Minn.: West Publishing Co., t. 5, 1007, nota 1,5, p. 71, sostiene que la norma del Código Civil francés fue traducida y usada como argumento en Hadley vs. Baxendale, y no hay duda que tuvo influencia en motivar a la Corte inglesa apara establecer esta regla tan frecuentemente aplicada en el Derecho angloamericano, tras lo cual remite al Tratado de las obligaciones de Pothier,

55 La falta de la alegación de la regla de la previsibilidad por parte de los demandados puede deberse a que no estaba claro si la acción era por incumplimiento de contrato o por tort. Alegando la "remoteness" del dańo se ponían a cubierto de los dos tipos de responsabilidad. 
en los primeros tratadistas. Chipman la silencia del todo ${ }^{56}$. Sedgwick la expone pero finalmente tampoco la recoge invocando la diferencia entre las acciones contractuales y las de tort. Seńala que tratándose de incumplimiento contractual el animus o la intención de la parte en falta es "entirely inmaterial", de modo que si el incumplimiento resulta de la inhabilidad o la malicia, la regla de los dańos es la misma. En cambio, en materia de torts, tratándose de "fraud or vexation", la compensación es mezclada con una pena, y el jurado tiene la más amplia discreción ${ }^{57}$. En la misma vista de Hadley, los abogados de los demandantes, si bien citan la distinción de Pothier en la versión dada por Sedgwick, la impugnan diciendo: "es dificultoso, sin embargo, ver cuál es el fundamento de este principio, y cómo el ingrediente del fraude puede afectar la cuestión. Por ejemplo, si los demandados habían maliciosa y fraudulentamente guardado la pieza, no resulta fácil ver por qué ellos deberían ser responsables por estos daños, si ellos no lo serían si la demora es ocasionada únicamente por su negligencia”.

De esta manera, la regla de la previsibilidad deducida del precedente de Hadley se aplica indistintamente al deudor culposo o doloso y así se ha mantenido en la jurisprudencia posterior.

\section{(3.3) El IMPACTO DE LA SENTENCIA HADLEY VS. BAXENDALE HASTA LA ACTUALIDAD}

El fallo de Hadley vs. Baxendale suscitó una inmediata aprobación general tanto en Inglaterra como en los Estados Unidos. Solo cuatro ańos después, el mismo Sedgwick, en la tercera edición de su tratado de 1858, reproducirá la doctrina de la sentencia luego de su afirmación de que el Código de la Louisiana expresa la verdadera regla aplicable a la materia ${ }^{58}$.

Los autores actuales no se cuestionan el tema y dan una aplicación general a la regla en todo incumplimiento contractual. La discusión ha girado sobre los criterios que permiten afirmar que el dańo fue contemplado por las partes. Un primer criterio, más restrictivo, ponía el acento en la voluntad: se utiliza del "tacit agreement test". Posteriormente, las Cortes se inclinan mayoritariamente por el "foreseeability test", que solo exige la previsibilidad pero no la presunción de un acuerdo tácito.

El Uniform Comercial Code 2-715 sigue la regla de la previsibilidad con bastante cercanía al precedente de Hadley ${ }^{59}$. Lo mismo se observa en

\footnotetext{
56 ChIPMAN (1822) 121-123.

57 SeDGWICK (1852) 61.

58 SEDGWICK, Theodore (1858). A Treatise on the Measure of Damages. $3^{3}$ edic. New York/ London: John S. Voorhies, Law Bookseller and Publisher; Sampson Low, son \& Co., p. 77.

59 Respecto de los dańos producidos por el incumplimiento del vendedor se dispone que " 2 . Los dańos indirectos que resultan del incumplimiento del vendedor incluyen: a) cualquier
} 
el Restatement on contracts second $\$ 351$ : "Los daños no son indemnizables si se trata de pérdidas que la parte incumplidora no tenía razón para prever como un resultado probable de su incumplimiento cuando el contrato fue celebrado"; añade que las pérdidas pueden ser previsibles si siguen "el curso ordinario de los eventos" o si "son el resultado de circunstancias especiales, más allá del curso ordinario de los eventos, pero que la parte incumplidora tenía razón para conocer" 60 .

La regla ha visto un reflorecimiento cuando varios autores de la corriente denominada Law an Economics han visto que ella aporta elementos de eficiencia al funcionamiento del mercado contractual poniendo de cargo del acreedor la carga de transferir al deudor la información relevante sobre sus intereses eventualmente afectados por el incumplimiento ${ }^{61}$.

\section{4) La doctrina de Pothier COMO PUNTO de ENCUENTRO ENTRE LOS DOS SISTEMAS: HACIA LA UNIFICACIÓN DEL DERECHO DE LOS CONTRATOS}

Como señala Carmen Domínguez, "la zona de influencia de las ideas de Pothier no se restringirá a los derechos que, por razones históricas, se identifican con el pensamiento jurídico galo, sino que, curiosamente, abarcará incluso a los comprendidos en la denominación genérica del Common law. Es una curiosidad, porque la conformación de esta última familia determina que la mayor parte de sus instituciones jurídicas no tenga un equivalente idéntico o al menos similar en los derechos codificados. La exigencia de previsibilidad en los dańos contractuales resarcibles es, por ello, una de las escasas oportunidades en las que las dos familias jurídicas confluyen en una misma solución, con algún matiz que en algo les distingue..." 62 .

Esta coincidencia común, que tiene su inicio en Pothier, puede tener mucha utilidad en los esfuerzos para uniformar o armonizar el Derecho

pérdida derivada de los requisitos o necesidades generales o particulares que el vendedor tenía motivos para conocer en el momento de contratar, y que no pudo ser razonablemente evitada mediante una compraventa de reemplazo o de otro modo...".

60 Así, FaRnsworth (2004) 258-260.

61 Posner, Richard (1986). Economic Analisys of Law. $3^{\text {a }}$ edic. Boston: Little Brown, p. 114; Danzing, Richard (1975). "Hadley v. Baxendale: A Study in the Industrialization of Law". Journal of Legal Studies 4, pp. 249-284; Bевснuck, Lucian Ayre Shavell, Steven (1991). "Information and the Scope of Liability for Breach of Contract: The Rule of Hadley v. Baxendale". Journal of Legal Economic and Organization 7, pp. 284-312. En lengua castellana, Gómez Pomar, Fernando (2002). Previsión de daños, incumplimiento e indemnización. Madrid: Civitas. También hay voces discordantes tanto con el fundamento económico como con la limitación de la regla de la previsibilidad: así, Eisennerg (1992) 563 ss., en particular 581-598. 
privado y allanar el camino para obtener un cierto nuevo Derecho común de las obligaciones y contratos.

La regla aparece en todos los proyectos que se proponen actualmente como bases para la elaboración de un Código europeo de contratos, que incluye unificar los criterios de Common law y de derecho continental (tanto de tradición francesa como germánica). Un primer esfuerzo iniciado en la misma Inglaterra es el Contract Code preparado por el profesor de la Universidad de Oxford, Harvey Mcgregor, por encargo de la Law Commission inglesa. Este proyecto dispone en el párrafo 437: "Solo es posible el resarcimiento por pérdidas si aquella parte contra la que se reclama: a) previó o tuvo razones para prever al tiempo del contrato que podría resultar responsable por incumplimiento del contrato, porque tal evento era una seria posibilidad, y b) puede ser razonablemente contemplado como habiendo contratado para responder"63.

Algo similar puede verse en los Principios de Unidroit sobre los Contratos Comerciales Internacionales (versión de 2004), que es muy similar incluso en sus términos a la doctrina de Pothier, pero sin excluir al deudor doloso: "Previsibilidad del daño.- La parte incumplidora será responsable solamente por el dańo que fue previsto o que podía razonablemente haber previsto al tiempo de la conclusión del contrato como probable resultado de su incumplimiento" (art. 7.4.4) ${ }^{64}$.

Como se ve tanto el Contract Code como los Principios Unidroit siguen la idea del Common law, que se distancia de Pothier, de no excluir al deudor que incumple por dolo. Lo contrario sucede con los proyectos de Código Europeo de los Contratos que llevan adelante el llamado grupo de Pavía, presidido por el profesor italiano G. Gandolfi y el grupo de trabajo de la Comisión para el Código Europeo de los Contrato presidida por el profesor sueco Ole Lando. El Proyecto de Pavía incluso va más allá, porque excluye de la regla de la previsibilidad no solo al deudor que incumple con dolo sino al que lo hace por culpa, quedando entonces solo aplicable la limitación para la responsabilidad estricta que sería la consagrada en el proyecto (el deudor responde siempre por el incumplimiento salvo que pueda probar causa extrańa). Así, el proyecto propone la siguiente disposición: "A menos que el deudor haya actuado por dolo o

Mcgregor, Harvey (1997). Contract Code. Proyecto redactado por encargo de la Law Commission inglesa. Traducción de José María de la Cuesta y Carlos Vattier. Barcelona: Bosh, pp. 116-118. En el comentario se seńala que el artículo tiene la base en Hadley vs. Baxendale. El texto quedó fijado cuando se abandonaron las discusiones en 1972, pero se hizo conocido en la Europa Continental en 1990 con motivo del encuentro de Pavía presididó por el profesor italiano Gandolfi.

64 El Internacional Institute for the Unification of Private Law, conocido como UNIDROIT, aprobó en 2004 la última versión del documento denominado Principles of International Commercial Contracts. El texto puede encontrarse en el sitio web: http://www.unidroit.org/ english/principles/contracts/main.htm [fecha de visita: 24 de diciembre de 2009]. 
culpa, debe responder del daño que -en atención al texto del contrato, a las circunstancias, a la buena fe y a los usos- debe razonablemente considerarse asumido implícitamente por él -en cuanto persona normalmente informada- en el momento de celebración del contrato" (art. $162 \mathrm{~N}^{\circ}$ $4)^{65}$. Algo similar se observa en el documento Principios europeos de Derecho de los Contratos, preparado por la Comisión Lando, aunque la excepción se limita al incumplimiento deliberado (doloso) y a la culpa grave; establece la siguiente regla: "Previsibilidad.- La parte que incumple solo responde de las pérdidas que haya previsto o que hubiera podido prever razonablemente en el momento de la conclusión del contrato como consecuencia lógica de su incumplimiento, salvo que el incumplimiento sea deliberado o gravemente negligente" (Artículo 9:503) ${ }^{66}$.

Pero no solo son proyectos y documentos recomendatorios los que ha acogido la regla de la previsibilidad forjada por Pothier. El importante tratado, también ratificado por Chile, que regula todas las compraventas de mercaderías que pueden considerarse internacionales se rigen por la llamada Convención de Viena sobre Compraventa Internacional de Mercaderías. Este tratado contempla expresamente la regla de la previsibilidad: "los daños no pueden exceder las pérdidas que la parte incumplidora previó o debió haber previsto al tiempo de la conclusión del contrato" (art. 74) ${ }^{67}$. Nuevamente, no se excepciona al deudor doloso.

Por lo visto, el futuro Derecho contractual común parece destinado a seguir lo que Pothier sistematizara y precisara con tanta lucidez en su Traité des obligations, y la única duda es si se adoptará su doctrina en forma completa, o con el matiz que le introdujo la tradición del Common Law de incluir en su limitación también al deudor que incumple con dolo.

\section{BIBLIOGRAFÍA}

- AтIYah, P. S. (1995). An Introduction to the Law of Contract. Oxford: Clarendon Press.

Clarendon Press.

(1979). The rise and fall of freedom of contract. Oxford:

65 García Cantero, Gabriel (2004). Traducción española de la Parte General del Código Europeo de Contratos. Santa Fe de Bogotá: Ediciones Academia Colombiana de Jurisprudencia.

66 Los Principios, partes I y II, son un documento preparado por la Commision on European Contract Law presidida por el profesor de la Copenhagen Business School, Ole Lando. El texto está disponible en: http://frontpage.cbs.dk/law/commission_on_european_contract_ law [fecha de visita: 24 de diciembre de 2009].

67 El título del tratado es Convención de las Naciones Unidas sobre los Contratos de Compraventa Internacional de Mercaderías. Fue aprobada por una conferencia diplomática, el 11 de abril de 1980 y entró en vigencia el 1 de enero de 1988. En Chile entró en vigor el 1 de marzo de 1991. 
- Barrientos Zamorano, Marcelo (2007). "Los dańos extrapatrimoniales que se previeron o pudieron prever al tiempo del contrato". Revista Chilena de Derecho, vol. 34, No 1, pp. 7-22.

- Bebchuck, Lucian Ayre Shavell, Steven (1991). "Information and the Scope of Liability for Breach of Contract: The Rule of Hadley v. Baxendale". Journal of Legal Economic and Organization 7, pp. 284312.

- Chipman, Daniel (1822). An essay on the Law of Contracts, for the payment of specific articles. Middlebury: J. W. Copelan.

- Corbin, Arthur Linton (1964). Corbin on Contracts. St. Paul, Minn.: West Publishing Co.

- Corral Talciani, Hernán (2008). "Causalidad y previsibilidad en la responsabilidad contractual". En Tatiana Vargas (editora): La relación de causalidad. Análisis de su relevancia en la responsabilidad civil y penal, Cuadernos de Extensión Jurídica 15. Santiago: Universidad de los Andes, pp. 115-179.

- Danzing, Richard (1975). "Hadley v. Baxendale: A Study in the Industrialization of Law". Journal of Legal Studies 4, pp. 249-284.

- Domat, Jean (1844). Las leyes civiles en su orden natural. Traducción de Felio Vilarruelas y José Sardá. Barcelona: Imprenta de José Taulo.

- Domínguez Hidalgo, Carmen (2000). El daño moral. Santiago: Editorial Jurídica de Chile.

- Ersenberg, Melvin Aron (1992). "The principle of Hadley v. Baxendale". California Law Review 80, pp. 563-613.

- Farnsworth, E. Allan (2004). Farnsworth on Contracts, $3^{a}$ edic. New York: Aspen.

- Faust, Florian (1994). "Hadley v. Baxendale: an undestandable miscarriage of justice". The Journal of Legal History, 15, 1, pp. 41-72.

- García Cantero, Gabriel (2004). Traducción española de la Parte General del Código Europeo de Contratos. Santa Fe de Bogotá: Ediciones Academia Colombiana de Jurisprudencia.

- Gómez Pomar, Fernando (2002). Previsión de daños, incumplimiento e indemnización. Madrid: Civitas.

- Jeztaz, Philippe Jamin, Christophe (2004). La doctrine. Paris: Dalloz.

- Jones, Williams (1828). An Essay on the Law of Bailments. $3^{a}$ edic. Philadelphia: O. Halsted y John Grigg.

- Kent, James (1827). Commentaries on American Law, t. 2. New York: O. Halsted.

- Martínez de Aguirre, Carlos (2004). "Robert Joseph Pothier". En Domingo, Rafael (editor), Juristas Universales. Madrid/Barcelona: Marcial Pons, t. II. 
- Mcgregor, Harvey (1997). Contract Code. Proyecto redactado por encargo de la Law Commission inglesa. Traducción de José María de la Cuesta y Carlos Vattier. Barcelona: Bosh.

- Posner, Richard (1986). Economic Analisys of Law. $3^{a}$ edic. Boston: Little Brown.

- Pothier, Robert Joseph (1802). A Treatise on Obligations, Considered in a Moral and Legal View. Newbern, N. C., Martin \& Orden. (1826). A Treatise on the Law of Obligations or Contracts. Traducción de Williams David Evans. London: Strahan, A. (1821), Oeuvres de Pothier (tomo I). Editadas por M. Siffrein. Paris, Videcoq. Gráficos Marypoint.

- Saint-Joseph, Anthoine (1856). Concordance entre les Codes Civils étrangers et le Code Napoleón. 2a edic. Paris: Cotillon, Libraire du Conseil d'État.

- Sedgwick, Theodore (1852). A treatise on the measure of damages or, an inquiry into the principes wich govern amount of compensation recovered in suits at law. $2^{\text {a }}$ edic. New York: John S. Voorhies, Law bookseller and Publisher.

- (1858). A Treatise on the Measure of Damages. $3^{\text {a }}$ edic. New York/London: John S. Voorhies, Law Bookseller and Publisher; Sampson Low, son \& Co.

- Zimmermann, Reinhard (2000). Estudios de Derecho Privado Europeo. Traducción de Antoni Vaquer Alox. Madrid: Civitas.

\section{JURISPRUDENCIA}

- Cox v. Troy, 1822, Barnewall and Alderson's Reports 474, p. 480.

- Williams v. Barton, 18 Louisiana R., 404; 13 La. 404, 410 (1839).

- Blanchard vs. Ely, 21 Wendell *348-350 (N.Y. 1839).

- Water vs. Towers 8 Ex. 401; 155 Eng. Rep. 1404 (1853).

- Hadley and Another v. Baxendale and Others (1854), 145, 9 Exchequer Reports 341. 